\title{
A PRODUÇÃO ACADÊMICA SOBRE ESTÁGIO CURRICULAR SUPERVISIONADO E A FORMAÇÃO INICIAL DE PROFESSORES: UMA ANÁLISE A PARTIR DE REVISTAS “QUALIS A/EDUCAÇÃO/CAPES”
}

\author{
THE ACADEMICAL PRODUCTION ABOUT SUPERVISED INTERNSHIP AND THE INITIAL \\ FORMATION OF PROFESSORS: AN ANALISIS OF THE JOURNALS "QUALIS \\ A/EDUCAÇÃO/CAPES"
}

PRODUCCION ACADÉMICA SOBRE PASANTÍA CURRICULAR Y LA FORMACIÓN INICIAL DE
PROFESORES: UN ANÁLISIS APARTIR DE REVISTAS “QUALIS A/EDUCACIÓN/CAPES”

\author{
Aline Resende Gomes \\ E-mail: aline r gomes@hotmail.com \\ Pedro Donizete Colombo Junior \\ Universidade Federal do Triângulo Mineiro - UFTM \\ E-mail: pedro.colombo.jr@gmail.com
}

\begin{abstract}
RESUMO
Esta pesquisa analisou a produção acadêmica de artigos científicos sobre estágio curricular supervisionado no processo de formação inicial de professores entre 2013 e 2015, tendo como fonte de consulta os periódicos classificados com QUALIS A1 e A2 da área de Educação de revistas Brasileiras. O recorte temporal justifica-se, uma vez que em 2015 foi divulgada a última atualização do QUALIS para a referida área. Adotamos metodologia de pesquisa qualitativa, focada na análise documental e com as ideias de Bardin (2011) para análise do conteúdo dos trabalhos. Nesta perspectiva analisamos 60 artigos que versam sobre Estágio. Dentre os resultados encontrados, nota-se ainda que há uma carência de publicações relacionadas ao estágio curricular supervisionado, principalmente na vertente de formação de professores, apenas $24 \%$. Em face de nossas análises, torna-se indispensável à maximização de pesquisas sobre a referida temática. Quiçá, mais indispensável ainda, a publicação de tais pesquisas de modo a socializar os resultados e contribuir com a área de formação de professores.
\end{abstract}

PALAVRAS-CHAVE: Estágio Curricular Supervisionado. QUALIS CAPES. Produção acadêmica.

\section{ABSTRACT}

This research analyzed the academic production of scientific articles about supervised internship in the process of initial formation of professors from 2013 to 2015, having as a consulting resource of the journals classified as QUALIS A1 and A2 from the field of Education of Brazilian Journals. The chosen period is justified, since in 2015 was published the last updating of QUALIS to the referred area. It was adopted the qualitative research methodology, focused on the documental analysis with the ideas of Bardin (2011) to the content analysis of the papers. Under this perspective, it was analyzed 60 articles that mentioned the Internship. Among the results it is perceived yet, the existence of a shortage of publications related to the supervised internship, mainly concerning about the teaching formation, only 24\%. In the light of these analyses, it becomes indispensable the maximization of researches about the referred theme. Perhaps, even more indispensable, the publication of such researches in order to socialize the results and contribute with the area of professor's formation.

KEYWORDS: A Supervised Internship. QUALIS CAPES. National's Academic Productions.

\section{RESUMEN}

Esta investigación analizó la producción académica de artículos científicos sobre pasantía curricular en el proceso de formación inicial de profesores entre 2013 y 2015, teniendo como fuente de consulta los periódicos 


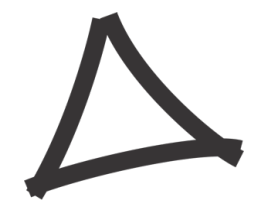

Revista Triângulo

www.seer.uftm.edu.br/revistaeletronica

clasificados con QUALIS A1 y A2 del área de Educación de revistas Brasileñas. El recorte temporal justificase, una vez que en 2015 fue divulgada la última actualización del QUALIS para la referida área. Adoptamos metodología de investigación cualitativa, con el foco en el análisis documental y con las ideas de Bardin (2011) para análisis del contenido de los trabajos. En esta perspectiva analizamos 60 artículos que versan sobre Pasantía. Entre los resultados encontrados, se ha notado todavía que hay una carencia de publicaciones relacionadas a la pasantía curricular, principalmente en el tratado de formación de profesores, solamente $24 \%$. En frente de nuestros análisis, se convierte indispensable la maximización de investigaciones de manera a socializar los resultados y contribuir con el área de formación de profesores.

PALABRAS-CLAVE: Pasantía Curricular. QUALIS CAPES. Producción académica.

\section{INTRODUÇÃ̃}

O estágio curricular supervisionado é uma importante ferramenta pedagógica no processo de formação inicial de professores, permitindo ao licenciando conhecer e ter acesso, ainda no papel de futuro professor, as especificidades da profissão que escolheu. García (1991, p. 39) ressalta que,

[...] aprender a ensinar é um processo que se inicia através da observação de mestres considerados "bons professores", durante um período de tempo prolongado. Isso significa trabalhar com um mestre durante um determinado período de tempo ao longo do qual o aprendiz adquire as competências práticas e aprende a funcionar em situações reais.

Desde modo, enfatiza-se que a presença de um bom professor formador - que sirva de exemplo e que ajude significativamente nesse processo de formação - faz com que seja constituída uma boa identidade profissional docente do licenciando.

O estágio curricular supervisionado, quando bem planejado pelo professor formador permite aos licenciandos apropriarem-se estratégias de ensino aprendizagem, compreendendo a importância do seu papel na formação inicial de professores. Nesse sentido, o estágio curricular supervisionado "visa ao aprendizado de competências próprias da atividade profissional e a contextualização curricular, objetivando o desenvolvimento do educando para a vida cidadã e para o trabalho" (BRASIL, 2008, s/p).

Contudo, Gatti e Barretto (2009) relatam certa vulnerabilidade por carência de planejamento e de compreensão na relação entre as instituições formadoras (Universidade e Educação Básica), e as formas de orientação e supervisão dos licenciandos. Na formação inicial de professores, os estágios curriculares supervisionados, seguem com lacunas a serem preenchidas, ou seja, muitas das vezes, é comum entre os licenciandos a interpretação de que o estágio configura-se a parte prática de seus cursos, fato que se confronta diretamente com a 


\section{$\Delta$}

ideia de uma formação integrada, na qual teoria e prática caminham juntas. Tal ideia corrobora com Pimenta e Lima (2004, p. 34) de que "[...] o estágio tem de ser teórico-prático, ou seja, que a teoria é indissociável da prática". Equívocos como o apresentado por licenciandos, por exemplo, tem feito com que futuros professores deixem as Universidades sem o preparo e a qualificação necessária para desempenhar suas atividades e atuar como profissionais docentes (CARVALHO, 1992; 2001).

No papel de estagiário, o professor em formação, geralmente, recorre às experiências já vivenciadas como um norte para seu trabalho in loco. É comum que o iniciante se inspire em professores que o motivaram a seguir a profissão e que ficaram marcados em seu percurso acadêmico-profissional. Da mesma forma, também é comum a busca por não repetir o que considera ineficaz para a formação dos alunos. Neste contexto, orientadores e supervisores de estágio curricular supervisionado contribuem imensamente neste processo de formação inicial.

Com o exposto, vislumbrando a importância de se pesquisar e divulgar sobre a temática estágio curricular supervisionado, esta pesquisa buscou analisar, a partir de um estudo do tipo "Estado da Arte", como as pesquisas sobre os estágios curriculares supervisionados de cursos de formação de professores vêm sendo (e se estão) socializadas com a comunidade acadêmica nos periódicos nacionais classificados com QUALIS/CAPES A (A1 e A2) da área de Educação. Mais especificamente, procurou-se analisar artigos que se encontravam disponíveis em banco de dados virtuais, por serem mais acessíveis a professores e pesquisadores e, por possibilitarem uma gama de acesso (online) universal, em detrimento das produções impressas. O recorte temporal desta pesquisa compreende os anos de 2013 a 2015, ou seja, os últimos três anos de publicações, uma vez que em 2015 foi divulgada a última atualização da classificação QUALIS para a área de Educação.

O QUALIS configura-se um sistema de avaliação usado para classificar a produção científica dos programas de pós-graduação, definido pela Coordenação de Aperfeiçoamento de Pessoal do Nível Superior do Ministério da Educação (CAPES/MEC) como sendo:

[...] o conjunto de procedimentos utilizados pela Capes para estratificação da qualidade da produção intelectual dos programas de pós-graduação. Tal processo foi concebido para atender as necessidades específicas do sistema de avaliação e é baseado nas informações fornecidas por meio do aplicativo Coleta de Dados. Como resultado, disponibiliza uma lista com a 


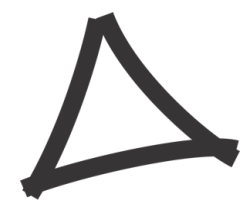

Revista Triângulo

www.seer.uftm.edu.br/revistaeletronica

classificação dos veículos utilizados pelos programas de pós-graduação para a divulgação da sua produção (CAPES, 2014, s/p, online).

Os periódicos, uma vez registrados são classificados em estratos de qualidade do mais elevado, chamado de A1, passando por A2, B1, B2, B3, B4, B5 até o menos elevado, chamado de C. Esta avaliação é realizada pelas áreas de conhecimento e passa por processo periódico de atualização. Esta avaliação é válida somente para periódicos que tenham recebido produção no ano ou período de classificação, no qual os pesquisadores e programas de pós-graduação se utilizam da lista gerada no momento da escolha de onde divulgar seus resultados de pesquisa. É importante ressaltar que

[...] o mesmo periódico, ao ser classificado em duas ou mais áreas distintas, pode receber diferentes avaliações. Isto não constitui inconsistência, mas expressa o valor atribuído, em cada área, à pertinência do conteúdo veiculado. Por isso, não se pretende com esta classificação que é específica para o processo de avaliação de cada área, definir qualidade de periódicos de forma absoluta (CAPES, 2014, s/p, online).

Em 2015 foi divulgada a última atualização da classificação QUALIS de Periódicos da área Educação para os anos de 2013 e 2014. Segundo a CAPES (2015), o QUALIS tem objetivo de "instrumentalizar a geração de indicadores de desempenho que serão utilizados no exercício de avaliação [...] apontar indicativos de melhorias e/ou aperfeiçoamentos no documento de Área e nos procedimentos para a avaliação quadrienal, bem como diretrizes para que os programas possam conduzir suas atividades visando ao seu aperfeiçoamento".

\section{REFERENCIAL TEÓRICO}

No que se refere ao Estado da Arte, Messina (1998, p. 01) explicita que este pode ser entendido como sendo "[...] um mapa que nos permite continuar caminhando [...] é também uma possibilidade de perceber discursos que em um primeiro exame se apresentam como descontínuos ou contraditórios [...]". Para Ferreira (2002, p. 258) as pesquisas do tipo Estado da Arte “[...] são reconhecidas por realizarem uma metodologia de caráter inventariante e descritivo da produção acadêmica e científica sobre o tema que busca investigar". O interesse por pesquisas que abordam o Estado da Arte se dá pela extensão desses estudos em apontar caminhos que vêm sendo adotados e de que modo são abordados, uma vez que permite mapear e refletir sobre o conhecimento já elaborado em várias fontes. 


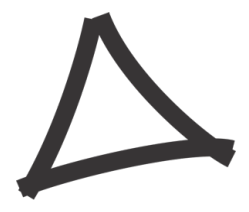

Revista Triângulo

www.seer.uftm.edu.br/revistaeletronica

A possibilidade de realização deste tipo de estudo, contribui para uma exploração de definição e, consequentemente, com pesquisas de um campo ou de uma área (ROMANOWSKI; ENS, 2006). Acrescenta-se o fato de que a análise documental, tal como consideram Lüdke e André (1986, p. 38) "pode se constituir numa técnica valiosa de abordagem de dados qualitativos, seja complementando as informações obtidas por outras técnicas, seja desvelando aspectos novos de um tema ou problema". A natureza das fontes, da pesquisa documental, baseia-se em materiais que não receberam um tratamento analítico, ou que ainda podem ser reelaborados de acordo com os objetivos da pesquisa (GIL, 2008, p. 51).

Como referencial teórico, adotamos as ideias de análise de conteúdo proposto por Bardin (2011) com o intuito de identificar o que tem sido pesquisado e divulgado sobre a temática estágio curricular supervisionado em periódicos nacionais QUALIS A/EDUCAÇÃO/CAPES.

Para a análise de conteúdo seguimos as indicações da autora, a qual explicita a importância de uma análise que contemple procedimentos como: uma leitura flutuante de modo a estabelecer o primeiro contato com os documentos a serem analisados. Então, a partir da escolha dos documentos, imprime-se a análise com (i) exaustividade, no qual se considera todos os elementos contidos no texto; (ii) representatividade, que resulta-se em uma amostra, a qual irá fazer parte representativa do universo inicial; (iii) homogeneidade, onde os documentos deverão seguir critérios e não podem apresentar singularidade fora desses critérios; (iv) pertinência, esses documentos devem ser adequados conforme a temática do estudo. Findado tais procedimentos, buscar-se-á pela formulação das hipóteses e dos objetivos, para uma afirmação provisória do analisado. Então, carece empregar a referenciação dos índices e a elaboração de indicadores, no qual após a leitura na íntegra dos documentos, e para a compreensão dos mesmos, busca-se a criação de itens para síntese do conteúdo (por exemplo, a criação de quadros analíticos).

Os procedimentos explicitados são classificados por Bardin (2011) como sendo um polo cronológico de pré-análise, os quais fornecem as condições necessárias de preparação do material com vistas à elaboração de conclusões a partir dos resultados encontrados. Contudo, Bardin (2011) também disserta sobre outros dois polos cronológicos da Análise de Conteúdo: a exploração do material e o tratamento dos resultados, inferências e interpretação. No presente estudo, os processos acima explicitados pautaram-se da escolha do material de 


\section{$\Delta$}

estudo, seguido da exploração do material encontrado e do tratamento dos resultados por meio de inferências e interpretação, as quais culminaram nas análises apresentadas no decorrer do trabalho em tela.

\section{MATERIAIS E MÉTODOS}

As etapas desenvolvidas constituíram-se de um levantamento dos artigos sobre estágio curricular supervisionado, disponíveis online referentes ao período de 2013 a 2015 dos periódicos nacionais classificados como QUALIS A pela CAPES. A opção por um banco de dados virtual justifica-se por acreditar que estes artigos são facilmente encontrados pelos pesquisadores da área de Educação e professores, uma vez que nem todos os periódicos impressos estão em sua forma online.

Realizamos uma consulta no site da Plataforma Sucupira ${ }^{1}$ dos periódicos A1 (Tabela 1) e A2 (Tabela 2). A lista de periódicos contempla as revistas nacionais e internacionais, entretanto, é importante ressaltar que para essa pesquisa utilizamos somente às revistas nacionais, pois acreditamos que estas são mais acessadas por pesquisadores e professores da área de Educação, em especial que investigam a temática estágio curricular supervisionado. Nesta consulta, encontramos 62 periódicos nacionais na área de Educação (70800006), QUALIS A. Optamos por utilizar somente o descritor "estágio", uma vez que este abrange as nomenclaturas semelhantes: estágio curricular supervisionado; estágio curricular; estágio supervisionado; dentre outros termos. Deste modo, não descartamos a possibilidade de outras publicações sobre a temática.

\section{TABELA 1: PERIÓDICOS NACIONAIS DA ÁREA DA EDUCAÇÃO COM QUALIS A1 - NÚMERO TOTAL DE ARTIGOS DO PERIÓDICO}

\begin{tabular}{|c|c|c|}
\hline ISSN & Título dos periódicos A1 nacionais & $\mathrm{N}^{0}$ de artigos \\
\hline $1414-4077$ & Avaliação (UNICAMP) & 89 \\
\hline $\begin{array}{l}1980-4415 / \\
0103-636 X\end{array}$ & BOLEMA : Boletim de Educação Matemática (Online) & 196 \\
\hline $0101-3262$ & Cadernos CEDES (Impresso) & 54 \\
\hline $0100-1574$ & $\begin{array}{l}\text { Cadernos de pesquisa (fundação Carlos Chagas. } \\
\text { impresso) }\end{array}$ & 51 \\
\hline $2178-2229$ & Cadernos de Pesquisa & 111 \\
\hline $1516-7313$ & Ciência \& Educação (UNESP. Impresso) & 180 \\
\hline $0101-7330 /$ & Educação \& Sociedade (Impresso) & 70 \\
\hline
\end{tabular}


Revista Triângulo

www.seer.uftm.edu.br/revistaeletronica

\begin{tabular}{|c|l|c|}
\hline $1678-4626$ & & \\
\hline $1517-9702$ & Educação e Pesquisa (USP.Impresso) & 167 \\
\hline $2175-6236 /$ & Educação e Realidade & 93 \\
$0100-3143$ & & 37 \\
\hline $0102-4698$ & Educação em Revista (UFMG. Impresso) & 89 \\
\hline $0104-4060$ & Educar em Revista (Impresso) & 104 \\
\hline $0104-4036$ & Ensaio (Fundação Cesgranrio. Impresso) & 69 \\
\hline $1676-2592$ & ETD: Educação Temática Digital & 14 \\
\hline $0104-5970$ & História, Ciências, Saúde-Manguinhos (Impresso) & 32 \\
\hline $1982-4327$ & Paidéia (USP. Online) & 59 \\
\hline $0103-7307$ & Pró-Posições (UNICAMP. Impresso) & 130 \\
\hline $0102-7972$ & Psicologia: Reflexão e Crítica (UFRGS. Impresso) & 37 \\
\hline $0102-3772$ & Psicologia: Teoria e Pesquisa (UnB. Impresso) & 104 \\
\hline $0102-6909$ & Revista Brasileira de Ciências Sociais (Impresso) & 126 \\
\hline $1413-2478 /$ & Revista Brasileira de Educação & 38 \\
\hline $1809-449 X$ & & 61 \\
\hline $1806-9347$ & Revista Brasileira de História (Online) & 0 \\
\hline $1519-5902$ & Revista Brasileira de História da Educação & \\
\hline $0102-2555$ & Revista da Faculdade de Educação (USP. Impresso) & 76 \\
\hline & (Cessou em 1998. Cont. ISSN 1517-9702 Educação e & 51 \\
\hline $0104-026 X$ & Resquisa (USP. Impresso)) & 67 \\
\hline $1646-401 X /$ & Revista Estudos Feministas (UFSC. Impresso) & \\
\hline $1645-7250$ & & \\
\hline $0104-8775$ & Varia História (UFMG. Impresso) & \\
\hline
\end{tabular}

\section{TABELA 2: PERIÓDICOS NACIONAIS DA ÁREA DA EDUCAÇÃO COM QUALIS A2 - NÚMERO TOTAL DE ARTIGOS DO PERIÓDICO}

\begin{tabular}{|c|l|c|}
\hline \multicolumn{1}{|c|}{ ISSN } & \multicolumn{1}{|c|}{ Título dos periódicos A2 nacionais } & $\mathbf{N}^{\mathbf{0}}$ de artigos \\
\hline $1981-5794$ & Alfa: Revista de Linguística (UNESP. Online) & 77 \\
\hline $2176-4573$ & Bakhtiniana: Revista de Estudos do Discurso & 77 \\
\hline $0104-8333$ & Cadernos Pagu (UNICAMP. Impresso) & 55 \\
\hline $1982-7806$ & Cadernos de História da Educação (Online) & 90 \\
\hline $1980-850 X$ & Ciência \& Educação & 122 \\
\hline $1645-1384$ & Currículo sem Fronteiras & 100 \\
\hline $0102-4450$ & $\begin{array}{l}\text { DELTA. Documentação de Estudos em Linguística } \\
\text { Teórica e Aplicada (PUCSP. Impresso) }\end{array}$ & 13 \\
\hline $0101-465 X$ & Educação (PUCRS. Impresso) & 82 \\
\hline $1519-387 X$ & Educação Unisinos & 77 \\
\hline $1982-596 X$ & Educação e Filosofia (Online) & 90 \\
\hline $1983-2117$ & Ensaio: Pesquisa em Educação em Ciências (Online) & 55 \\
\hline $0103-2186$ & Estudos Históricos (Rio de Janeiro) & 67 \\
\hline $1518-0158$ & Estudos de Literatura Brasileira Contemporânea & $1 S 5$ \\
\hline
\end{tabular}


Revista Triângulo

www.seer.uftm.edu.br/revistaeletronica

\begin{tabular}{|c|l|c|}
\hline $1678-4669$ & Estudos de Psicologia (Natal. Online) & 81 \\
\hline $0103-166 X$ & Estudos de Psicologia (PUCCAMP. Impresso) & 179 \\
\hline $0103-6831$ & Estudos em Avaliação Educacional (Impresso) & 112 \\
\hline $2236-3459$ & História da Educação & 61 \\
\hline $1414-3283$ & Interface (Botucatu. Impresso) & 210 \\
\hline $1518-8795$ & Investigações em Ensino de Ciências (Online) & 104 \\
\hline $2176-2767$ & Projeto História (Online) & 77 \\
\hline $1809-4309$ & Práxis Educativa (UEPG. Online) & 61 \\
\hline $1807-0310$ & Psicologia \& Sociedade (Online) & 261 \\
\hline $1807-0329$ & Psicologia em Estudo (Online) & 119 \\
\hline $1415-3203$ & Repertório Teatro \& Dança (Impresso) & 102 \\
\hline $1413-6538$ & Revista Brasileira de Educação Especial & 0 \\
\hline $1806-5104$ & Revista Brasileira de Pesquisa em Educação em & 84 \\
& Ciências & 59 \\
\hline $1678-166 X$ & Revista Brasileira de Política e Administração da & 80 \\
\hline & Educação & 97 \\
\hline $1981-2582$ & Revista Educação (PUCRS. Online) & 138 \\
\hline $1981-1802$ & Revista Educação em Questão (Online) & 73 \\
\hline $0104-7043$ & Revista FAEEBA & 0 \\
\hline $2175-3539$ & Revista Psicologia Escolar e Educacional & 41 \\
\hline $1982-7830$ & Revista da ANPOLL (Online) & 82 \\
\hline $0104-5962$ & Revista de Educação Publica (UFMT) & 32 \\
\hline $0020-3874$ & Revista do Instituto de Estudos Brasileiros & 19 \\
\hline $1809-3876$ & Revista e-Curriculum (PUCSP) & \\
\hline $0103-2070$ & Tempo Social (USP. Impresso) & \\
\hline $1516-5159$ & Via Atlântica (USP) & \\
\hline
\end{tabular}

\section{ANÁLISE DOS DADOS E RESULTADOS}

A partir da adoção das ideias de análise de conteúdo de Bardin (2011) iniciamos a leitura flutuante dos documentos encontrados (periódicos), de modo a estabelecer o primeiro contato e seleção de artigos para análise futura. Buscamos, desta forma, identificar os artigos presentes nos periódicos que contemplassem o descritor "estágio" em qualquer parte do texto e, também que foram publicados entre os anos 2013 a 2015.

Com o universo demarcado, escolha dos documentos, passamos à regra da exaustividade, na qual acessamos periódicos por periódicos e realizamos o download dos artigos selecionados de forma a não deixar de fora qualquer elemento. Feito isto, passamos para a regra da representatividade, que se resulta em uma amostra, no caso, artigos com o descritor estágio, a qual irá fazer parte representativa do universo inicial. 


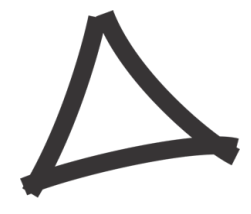

Posteriormente, definimos analisar apenas artigos completos, ou seja, que pudessem ser lidos na íntegra, regra da homogeneidade. Cabe destacar que foram descartados os artigos que traziam o descritor "estágio" como sinônimo de fase, etapa, momento, período, etc., assumindo assim a regra de pertinência em relação à temática de estudo. Frente ao exposto, localizamos 60 produções que abordavam a temática estágio curricular supervisionado, publicadas em um escopo de apenas 23 dos 62 periódicos analisados.

Desta forma, a análise detalhada contemplou 60 artigos, os quais foram lidos na íntegra, e para uma melhor compreensão dos mesmos, foram criadas "marcas" para síntese dos conteúdos, como: autor, universidade onde se realizou a pesquisa, periódico de publicação, ano de publicação, título do estudo, metodologia adotada na pesquisa, instrumento de coleta de dados, tipos de sujeitos participantes da pesquisa, objetivo e curso caracterizado. Com isso foi possível realizar uma elaboração de indicadores, e algumas categorias foram criadas, por exemplo: Instituição de Ensino: instituição onde foi realizado o estudo para a produção do artigo; Cursos em que foi realizado o Estudo: quais os cursos que estão abordando a temática e qual a sua predominância nos periódicos; Estágio e Formação de Professores: o estágio curricular supervisionado como importante ferramenta pedagógica no processo de formação de professores; Estágio e Escola: essa categoria se constitui dos trabalhos que resultaram em um objeto educacional, para melhoria da Educação Básica; Estágio e História: trabalhos que relatam a história de um determinado curso ou uma revisão bibliográfica do tema; Estágio e Linguística: os estudos que utilizam de alguma ferramenta do estágio curricular supervisionado para trabalhar com o discurso dos participantes dos mesmos; Estágio e Saúde: artigos com estágios curriculares supervisionados realizados na área da saúde ou com cursos desse mesmo campo; Estágio e Outros temas: esta categoria relaciona com estágios curriculares supervisionados em outros espaços educacionais além do ambiente escolar.

Em meio nossas análises, encontramos 38 artigos (63\%) dentre os periódicos de estrato A2 publicados dentre os anos de 2013 a 2015. Dentre os periódicos de estrato A1 foram encontrados 22 artigos (37\%). Neste recorte temporal - triênio - a concentração de publicações se encontra no ano de 2014 com 25 artigos (42\%), o ano de 2015 com 20 artigos (33\%) e por último, o ano de 2013 com 15 artigos (25\%). 


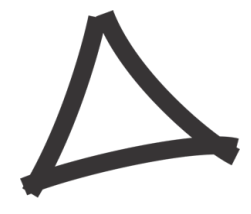

Sobre a autoria dos trabalhos, os 60 artigos analisados contemplam ao todo centenas de autores. A título de nota, considerando apenas primeiro e segundo autores registra-se um total de 103 autores. Apesar do grande número de autores, apenas destes aparecem com mais de uma publicação (duas), registrando publicações nos periódicos "Revista Educação em Questão" (QUALIS A2), "Cadernos de Pesquisa" (QUALIS A1) e "Educação Usininos" (QUALIS A2).

Em nosso mapeamento, 44 Instituições de Ensino Superior (IES) foram identificadas como locais de estudo dos 60 artigos científicos sobre a temática estágio curricular supervisionado e, sendo a maioria IES públicas (57\%). Dentre os artigos encontrados quatro $(7,1 \%)$ fazem referencia a Universidade Estadual Paulista - UNESP, sendo o maior volume encontrado em relação a uma instituição. A Universidade de São Paulo - USP e na Universidade Federal de Goiás - UFG, foram referendadas com três artigos (5,3\%) cada. As instituições: Universidade Federal de São Carlos - UFSCar, Universidade Estadual de Maringá - UEM, Universidade Federal de Minas Gerais - UFMG, Universidade Federal da Fronteira do Sul - UFFS, Universidade Federal de Rio Grande do Sul - UFGS, Universidade de Brasília - UnB, Universidade Federal de São Paulo - UNIFESP e Universidade Federal da Bahia - UFBA, foram referendadas em dois artigos cada (3,6\%). Outras 33 IES aparecem indicadas em um artigo cada (1,8\%). Foram nove artigos sem mencionar a IES de estudo e dois relativos a universidades de Portugal.

As análises evidenciaram que a região Sudeste foi a que contribuiu com a maior parte da produção (37,9\%), distribuída entre os estados de São Paulo (24,1\%), Minas Gerais (8,5\%) e Rio de Janeiro (5,3\%). Em seguida, a região Sul apareceu com 24,1\%, onde todos os estados foram contemplados: Rio Grande do Sul (12\%), Paraná (8,6\%) e Santa Catarina (3,5\%). A região Centro-Oeste aparece com 13,7\% dos artigos produzidas, sendo em Goiás $(6,9 \%)$, Distrito Federal (3,4\%), Mato Grosso e Mato Grosso do Sul, ambos com 1,7\%. Na Região Nordeste $(6,8 \%)$ houve a publicação de artigo científico oriundos dos estados: Bahia, Ceará, Paraíba e Piauí com 1,7\% cada. Por último, a região Norte $(3,4 \%)$, sendo os estados do Pará e Tocantins, os dois com 1,7 \%. Em seis artigos (10,3\%), não foi possível identificar os Estados e dois $(3,4 \%)$ são referentes a Portugal. Inferimos que este resultado possa reforçar a ideia de Carneiro (2011) de que as regiões Sudeste e Sul do país por terem um grande número de programas de pós-graduação, Universidades e grupos de pesquisa, têm maior número de 


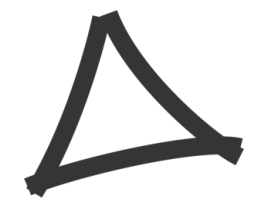

Revista Triângulo

www.seer.uftm.edu.br/revistaeletronica

investimento no âmbito acadêmico. Desta forma, o autor enfatiza que "tendo em vista a distribuição econômica do Brasil, é de se esperar que a pesquisa científica mais qualificada seja originada nos polos científicos incrementados pelas políticas de pós-graduação" (CARNEIRO, 2011, p. 99).

O periódico que concentrou o maior número de artigos sobre estágio curricular supervisionado foi Interface, de Botucatu, com um total de doze (20\%), seguido pela BOLEMA: Boletim de Educação Matemática, com nove (15\%), Currículo sem Fronteiras e, Educação Unisinos ambas com cinco (8,3\%), Educação e Pesquisa, Educação em Revista, Estudos em Avaliação Educacional e, Revista Educação em Questão ambas com três (5\%), Cadernos de Pesquisa, Alfa: Revista de Linguística da UNESP, Bakhtiniana: Revista de Estudos do Discurso e Ensaio: Pesquisa em Educação em Ciências, cada artigo com dois $(3,4 \%)$ e Ciência \& Educação da UNESP, Educação e Realidade, Psicologia: Reflexão e Crítica da UFRGS, Revista Brasileira de Educação, Revista Lusofona de Educação, DELTA: Documentação de Estudos em Linguística Teórica e Aplicada da PUCSP, Educação da PUCRS, Psicologia em Estudo e Revista Psicologia Escolar e Educacional, um artigo por periódico $(1,7 \%)$. Os demais periódicos não contemplavam nenhum artigo com o descritor "estágio".

A partir destes dados e da Tabela 1 e 2 e, das análises mencionadas acima, podemos perceber que o número total de artigos e o número de artigos com descritor "estágio", de cada periódico diferem consideravelmente. Apesar de identificarmos 62 periódicos contendo o total de 5.082 artigos disponibilizados online na sua forma completa, somente alguns periódicos contemplam o descritor que desejávamos.

Verificamos também, a metodologia utilizada pelas pesquisas. Encontramos que o estudo de caso foi utilizado em 27 artigos (42,9\%), seguido pela metodologia bibliográfica em 15 artigos (23,8\%), e investigativa em 08 artigos (12,7\%). Análise do discurso (metodologias tanto Bakthiana quanto Foucautiana) em 07 artigos (11,1\%). Pesquisa-exploratória em 02 artigos (3,2\%). História oral, narrativa-biográfica, pesquisa-ação, práticas docentes aparecem, cada uma delas, em 01 artigo (1,6\%). Apenas dois trabalhos $(3,2 \%)$ não informaram a metodologia adotada (Gráfico 1). A diversidade de processos metodológicos e o avanço das pesquisas, na área de formação de professores, se dão pela 
[...] combinação de diferentes formas de coleta de dados. Muitos pesquisadores associam a entrevista com o exame de documentos, outras vezes com questionário ou com observação. Tal variedade de fontes de coleta indica uma abordagem mais ampla das questões sobre formação de professores, o que traz maior riqueza para a área (ANDRÉ, 2010, p. 179).

\section{GRÁFICO 1 - QUANTITATIVO DA METODOLOGIA DOS ESTUDOS SOBRE ESTÁGIO NOS 60 ARTIGOS EM PERIÓDICOS NACIONAIS (2013-2015).}

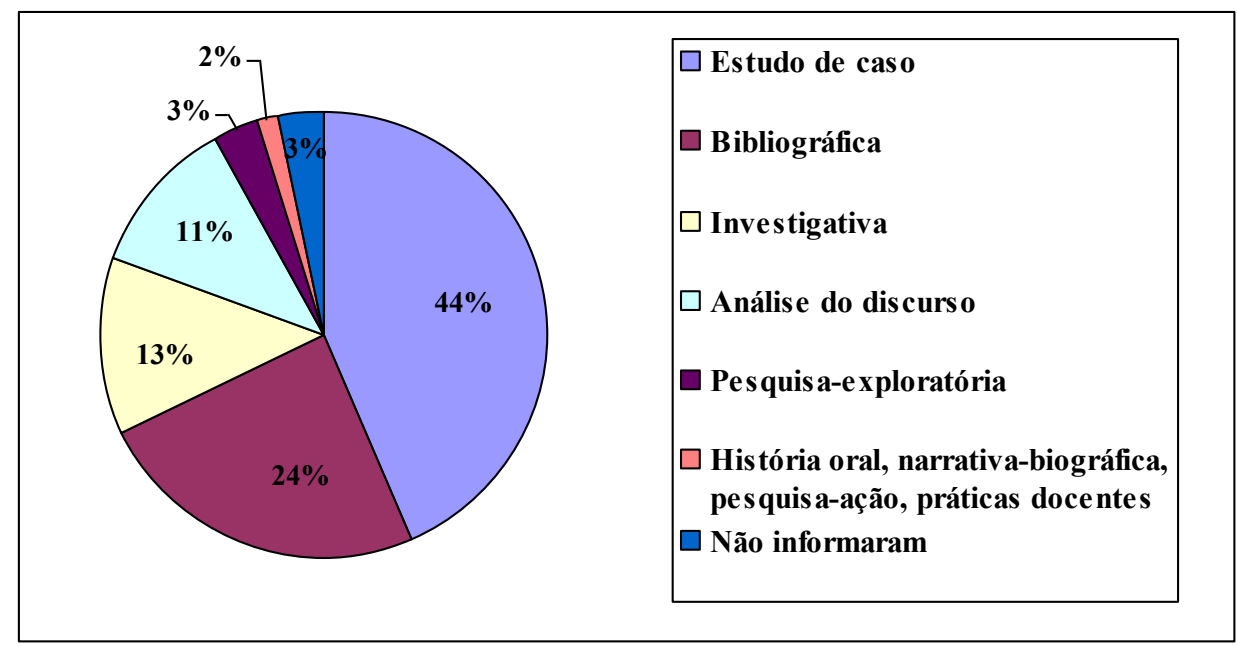

A partir do processo de investigação, podemos perceber a variação, a forma e a densidade que as análises apresentam em relação à metodologia utilizada pelas pesquisas: pesquisa-ação, história oral, narrativa-biográfica e outros. Entretanto, a apreciação dos trabalhos evidenciou que muitos tratamentos de análise de dados ficam restritos aos depoimentos dos sujeitos apenas, não interpolando outras formas de análise em suas metodologias. Desta forma, concordamos com André (2010) de que é "necessário dar um passo além, aprofundar as análises e interpretações, de modo que se possa gerar um conhecimento mais abrangente e consistente" (p. 179).

No que tange aos instrumentos de coleta de dados utilizados pelos artigos analisados, identificamos que o relatório de estágio curricular supervisionado foi empregado em catorze artigos (17,7\%). Posteriormente, a entrevista em doze artigos (15,2\%), seguido pelo questionário e pela coleta documental, onde cada uma delas encontra-se em nove artigos $(11,4 \%)$. Análise do conteúdo, grupo focal e prática oral, aparecem respectivamente em oito $(10,1 \%)$, sete $(8,9 \%)$ e seis $(7,6 \%)$ artigos. Observação e narrativa em quatro artigos $(5 \%)$, 


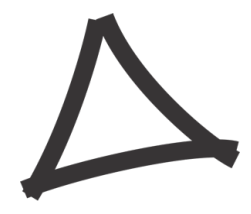

Revista Triângulo

www.seer.uftm.edu.br/revistaeletronica

estudo de caso em dois artigos (2,5\%). Estado da arte, bibliografia, blog, pesquisa de campo mostram-se em um artigo $(1,3 \%)$ cada uma delas.

Em relação aos cursos contemplados pelas pesquisas, o Curso de Licenciatura em Matemática foi o com maior representatividade nos trabalhos, com nove trabalhos (12\%). Inferimos que este resultado tenha se sobressaído, uma vez que, o periódico BOLEMA: Boletim de Educação Matemática, o qual trabalha especificamente a temática Matemática e este foi um dos com o maior número de artigos. Os cursos de Pedagogia, Letras e Educação Física com cinco trabalhos; os cursos de Licencitura, História, Física e Química, cada um com dois artigos;o curso de Geografia com um artigo. Em um outro viés, chama a atenção os resultados de artigos publicados em periódicos da área de Educação sobre o descritor "estágio" desvinculado de cursos de formação de professores. Nestes casos, obtivemos: no curso de Odonlogia seis trabalhos, referentes ao curso de Psicologia, quatro trabalhos; ao curso de Enfermagem e Artes Visuais três estudos; os cursos de Nutrição e Fisioterapia cada um com dois artigos; e os cursos de Gestão de Políticas Públicas, Ciências Naturais, Administração, Teatro, Tecnológicos, Ciências da Natureza, Educação Intercultural, Medicina, Farmácia, Engenharia e Terapia Ocupacional com um trabalho cada.

Como mencionado, apesar da variedade dos cursos encontrados, percebemos que muitos não estão relacionados com o processo de formação de professores, mesmo oriundos dos periódicos da área da Educação (QUALIS/CAPES), sendo esta uma inquietação, pois em nossa análise, são poucos os artigos que discutem sobre a temática, e a maioria destes específicos de outras áreas de formação. Além dessas categorias, subdividimos os artigos em seis subcategorias temáticas, para uma devida comparação da análise dos achados: Estágio e Formação de Professores, Estágio e Saúde, Estágio e História, Estágio e Outros tema, Estágio e Linguística e Estágio e Escola.

A categoria mais enfatizada nos periódicos foi Estágio e Formação de Professores, com catorze artigos (24\%), uma vez que quatro destes retrata o desenvolvimento da identidade profissional docente por meio dos estágios curriculares supervisionados; quatro relacionados à viabilidade do estágio curricular supervisionado como alternativa a prática docente; três sobre a estruturação dos estágios curriculares supervisionados para a necessária formação de professores e três a respeito da compreensão do papel da orientação de estágio curricular supervisionado. Apesar de a categoria Estágio e Formação de Professores ser a 


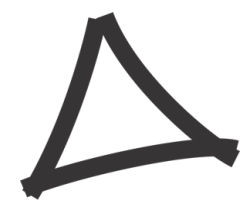

Revista Triângulo

www.seer.uftm.edu.br/revistaeletronica

mais presente, os resultados mostram que são poucos estudos relevantes quando se refere ao estágio curricular supervisionado principalmente, no contexto do processo de formação inicial de professores, pois nestes não aparecem com grande ênfase nas discussões e são poucas pesquisas à garantia desse processo.

Nos achados, a categoria Estágio e Saúde, com treze artigos (21\%) foram identificados, sendo que cinco são sobre o desempenho e experiências de alunos no estágio curricular supervisionado na área da saúde; três relacionados à atuação do estagiário especificamente no Sistema Único de Saúde (SUS); três direcionados aos profissionais da saúde e docência, e as dificuldades sobre o ensino-serviço e dois relatando a saúde do trabalhador de saúde. Apesar do estágio curricular supervisionado não está vinculado com a formação inicial de professores, uma vez sendo o objetivo do nosso estudo, não podemos desconsiderar que a influência do estágio curricular supervisionado na formação acadêmica do profissional da área da saúde.

Sobre a temática Estágio e História, com onze artigos (18\%), onde cinco referem a uma revisão da literatura sobre o assunto; três relatam a organização curricular dos cursos; dois contam a história dos cursos de licenciatura ou pedagogia e um sobre a legislação do estágio curricular supervisionado. Sobre o tema Estágio e Outros temas, registramos dez artigos (17\%), no qual três investigam sobre a matriz curricular; dois sobre estado da arte; dois utilizando blogs e/ou tecnologias; um sobre o estágio curricular supervisionado cultural no âmbito indígena; um empregando o teatro e um sobre as dimensões da representação social sobre o "ser professor". Na categoria Estágio e Linguística, levantamos nove artigos (15\%), onde quatro utilizaram a teoria Bakhtiniana; dois empregaram a análise do discurso do relatório de estágio curricular supervisionado; dois sobre reflexões na escrita dos relatórios e usou a análise do discurso Foucaultiana.

Compuseram os artigos sobre Estágio e Escola, com três (5\%), sendo um sobre o estudo do conteúdo do ensino médio pra melhor compreensão das professoras do mesmo; um consistindo no desenvolvimento de um objeto educacional e um sobre a variação de comportamento dos alunos nas aulas de diferentes professores da Educação Básica. O Gráfico 2 demonstra o quantitativo de artigos encontrados e sua respectiva subcategorização:

GRÁFICO 2 - QUANTITATIVO DA SUBCATEGORIZAÇÃO DOS ESTUDOS SOBRE ESTÁGIO NOS 60 ARTIGOS EM PERIÓDICOS NACIONAIS (2013-2015). 


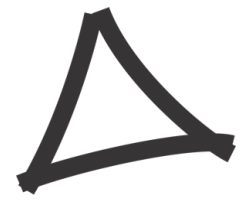

Revista Triângulo

www.seer.uftm.edu.br/revistaeletronica

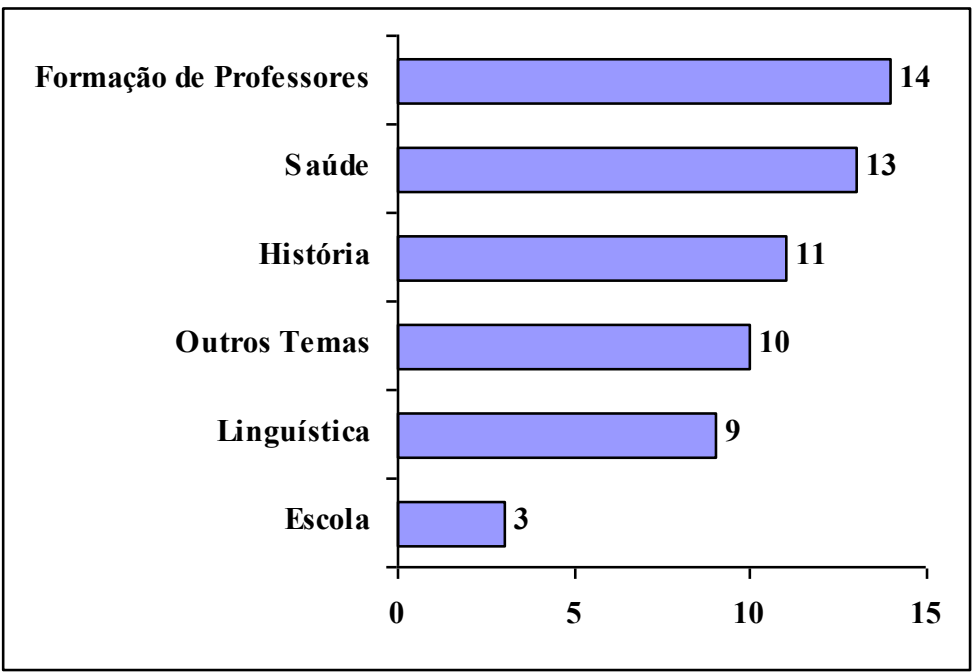

Embora o maior quantitativo seja da categoria Estágio e Formação de Professores, conforme o Gráfico 2, esperávamos mais em relação à quantidade de artigos iniciais, atribuímos como justificativa para essa discrepância, que muitos estudos estão centralizados no professor, e de certo modo, desviando a atenção do processo de formação inicial de professores. Isso causa certa inquietação, uma vez faz-se necessário conhecimento para ensinar aos futuros professores como enfrentar a realidade educacional do século XXI.

\section{CONSIDERAÇÕES FINAIS}

Nos últimos dez anos, o número de estudos e pesquisas sobre formação de professores aumentou consideravelmente (ANDRÉ, 2010). Fato que tem refletido diretamente nas discussões e apresentações realizadas em eventos científicos, na mídia e em publicações em periódicos científicos. Coube a esta investigação questionar e verificar como tem sido abordado o estágio curricular supervisionado no contexto de pesquisa sobre a formação docente. Desta forma buscamos contribuir com esta discussão levantando o que tem sido publicado em periódicos QUALIS A/Educação/CAPES sobre a temática. O QUALIS é um meio de classificação da divulgação de produção bibliográfica dos programas de pósgraduação stricto sensu, sendo os periódicos com conceito A considerados de maior relevância para divulgação dos resultados de pesquisas entre os pares no meio científico.

Com base nas análises realizadas, deparamo-nos com um cenário em que são ínfimas as publicações de trabalhos que versam sobre o estágio curricular supervisionado em 


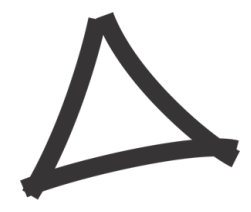

periódicos nacionais QUALIS A, quando comparados ao escopo total das publicações dos periódicos da área de Educação. Ademais, são poucos os trabalhos que abordam o tema estágio curricular supervisionado com foco na formação inicial de professores, sendo encontrado em nossa análise apenas $24 \%$. Fato este que permite concluir ser esta uma temática pouco investigada e discutida pela academia, apesar de sua importância para a formação docente ou pesquisada e não publicada em periódicos considerados, segundo critérios da CAPES, como sendo os melhores periódicos.

Além de serem poucos trabalhos que versam sobre estágio curricular supervisionado, muitos não estão relacionados à área de formação docente, mesmo sendo publicados na área da Educação (QUALIS/CAPES). Fato este constatado ao listarmos os diferentes cursos dos quais os artigos derivaram. Entendemos que é fundamental ampliar e divulgar os estudos sobre a temática estágio em cursos de Licenciatura, principalmente nos periódicos de maior QUALIS.

É importante destacar, a partir da análise desse mapeamento, o avanço da metodologia e novas formas de coleta de dados, em pesquisas com a temática estágio curricular supervisionado, como: análise do discurso, narrativa-biografica, pesquisa-ação, blog, que possibilita explorar novos aspectos do caso, de modo que as análises sejam enriquecidas.

Pereira (2000) descreve que formar professores é uma tarefa bastante complexa e, de um modo geral, apresenta "velhos problemas", porém, sempre "novas questões". Neste sentido, tornam-se indispensáveis que se tenham pesquisas sobre esta temática, porém, quiçá, mais indispensável ainda à publicação de tais pesquisas de modo a socializar os resultados encontrados e contribuir com a área de formação de professores.

Neste sentido, entendemos que o trabalho em tela pode contribuir (re)pensar tais questões. Esperamos também contribuir para que outros pesquisadores compreendam a relevância de publicar as pesquisas relacionadas ao estágio curricular supervisionado para a formação inicial de professores e a partir disso, proporcionar uma visão de suas necessidades e desafios a serem enfrentados. Enfim, que esta pesquisa possa fomentar uma reflexão sobre a importância das publicações relacionadas ao estágio curricular supervisionado e sua íntima relação com uma sólida formação docente.

\footnotetext{
1 A consulta sobre a classificação dos periódicos QUALIS era feita por meio do WebQualis, um aplicativo online do sistema CAPES. Entretanto, a partir de 2015, a classificação dos veículos de divulgação dos programas
} 


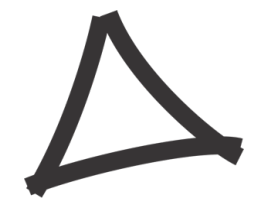

Revista Triângulo

www.seer.uftm.edu.br/revistaeletronica

de pós-graduação está sendo realizada no módulo QUALIS/CAPES da Plataforma Sucupira, que está disponível em:

$<$ https://sucupira.capes.gov.br/sucupira/public/consultas/coleta/veiculoPublicacaoQualis/listaConsultaGeralPerio dicos.jsf $>$.

\section{REFERÊNCIAS}

ANDRÉ, M. Formação de professores: a constituição de um campo de estudos. Educação, v. 33, n. 3, p. 174-181, 2010.

A pesquisa sobre formação de professores: contribuições à delimitação do campo. In: DALBEN, Ângela I.L.F. et al. Didática: convergências e tensões no campo da formação e do trabalho docente. Belo Horizonte: Autêntica, 2010. p. 273-283.

BARDIN, L. Análise de Conteúdo. São Paulo; Edições 70, 2011. 279 p.

BRASIL. Lei $\mathbf{N}^{\circ} 11.788$ de 25 de setembro de 2008. 2008. Disponível em: <http://www. planalto.gov.br/ccivil_03/_ato2007-2010/2008/lei/111788.htm>. Acesso em: 10 nov. 2016.

CARNEIRO, F. F. B. Políticas científicas em educação física: a arqueologia do GTT Escola no Congresso Brasileiro de Ciências do Esporte (1997-2009). 2011. $162 \mathrm{f}$. Dissertação (Mestrado)- Programa de Pós-Graduação em Educação Física, Universidade Federal do Espírito Santo, Vitória, 2011.

CARVALHO, A. M. P. Reformas nas licenciaturas: a necessidade de uma mudança de paradigma mais do que de mudança curricular. Em Aberto, Brasília, ano 12, n. 54, p. 51-63, 1992.

. A influência das mudanças da legislação na formação dos professores: As 300 horas de estágio supervisionado. Ciências \& Educação, Bauru, v. 7, n. 1, p. 113-122, 2001.

COORDENAÇÃO DE APERFEIÇOAMENTO DE PESSOAL DO NÍVEL SUPERIOR. Ministério da Educação. Fundação CAPES. Qualis. Brasília; CAPES; 2014. Disponível em: $<$ http://www.capes.gov.br/component/content/article?id=2550:capes-aprova-a-novaclassificacao-do-qualis $>$. Acesso em: 08 nov. de 2016.

. Ministério da Educação. Fundação CAPES. Critérios de classificação Qualis. Brasília; CAPES; 2015. Disponível em: https://www.capes.gov.br/images/stories/download/avaliacaotrienal/Docs_de_area/qualis/ensi no.pdf $>$. Acesso em: 08 nov. de 2016.

FERREIRA, N. S. A. As pesquisas denominadas 'Estado da Arte'. Educação \& Sociedade, v. 23, n.79, p.257- 272, 2002.

GARCÍA, C. M. Estrutura conceitual da formação de professores. In: Formação de professores para uma mudança educativa. Lisboa: Porto Editora, 1991, p. 18-68. 


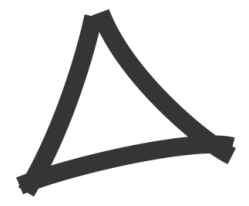

Revista Triângulo

www.seer.uftm.edu.br/revistaeletronica

GATTI, B. A.; BARRETTO, E. S. S.. Professores do Brasil: impasses e desafios. Brasília: Unesco, 2009.

GIL, A. C. Métodos e técnicas de pesquisa social. 6. ed. São Paulo: Atlas. 2008. Disponível em: $\quad<$ https://ayanrafael.files.wordpress.com/2011/08/gil-a-c-mc3a9todos-e-tc3a9cnicas-depesquisa-social.pdf $>$. Acesso em: 20 dez. 2016.

LÜDKE, M., ANDRÉ, M.E.D.A. Pesquisa em educação: abordagens qualitativas. São Paulo: EPU, 1986.

MESSINA, G. Estudio sobre el estado da arte de la investigacion acerca de la formación docente en los noventa. Organización de Estados IberoAmericanos para La Educación, La Ciência y La Cultura. In: Reúnion de consulta técnica sobre investigación en formácion del professorado, 1998, México. Anais eletrônicos... México, 1998.

PEREIRA, J. E. D. Formação de professores: pesquisa, representações e poder. Belo Horizonte: Autêntica, 2000, p. 76.

PIMENTA, S. G.; LIMA, M. S. L. Estágio e Docência. São Paulo: Cortez, 2004.

ROMANOWSKI, J. P.; ENS, R. T. As pesquisas denominadas do tipo "estado da arte" em educação. Diálogo Educ. Curitiba, v.6, n.19, p.37-50, set./ dez. 2006. Disponível em $<\mathrm{http}$ ://www2.pucpr.br/reol/pb/index.php/dialogo?dd1=237\&dd99=view\&dd98=pb $>$. Acesso em: 29 nov. 2016. 